\title{
The targeting and functions of miRNA-383 are mediated by FMRP during spermatogenesis
}

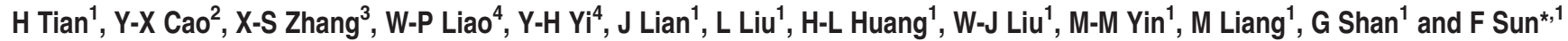

Our previous studies have shown that microRNA-383 (miR-383) expression is downregulated in the testes of infertile men with maturation arrest (MA). Abnormal testicular miR-383 expression may potentiate the connections between male infertility and testicular germ cell tumors. However, the mechanisms underlying the targeting and functions of miR-383 during spermatogenesis remain unknown. In this study, we found that fragile $X$ mental retardation protein (FMRP) was associated with 88 miRNAs in mouse testis including miR-383. Knockdown of FMRP in NTERA-2 (NT2) (testicular embryonal carcinoma) cells enhanced miR-383-induced suppression of cell proliferation by decreasing the interaction between FMRP and miR-383, and then affecting miR-383 binding to the $3^{\prime}$-untranslated region of its target genes, including interferon regulatory factor-1 (IRF1) and Cyclin D1 both in vivo and in vitro. On the other hand, FMRP levels were also downregulated by overexpression of miR-383 in NT2 cells and GC1 (spermatogonia germ cell line). miR-383 targeted to Cyclin D1 directly, and then inhibited its downstream effectors, including phosphorylated $\mathrm{pRb}$ and E2F1, which ultimately resulted in decreased FMRP expression. Reduced miR-383 expression, dysregulated cyclin-dependent kinase 4 expression (one of the downstream genes of miR-383) and increased DNA damage were also observed in the testes of Fmr1 knockout mice and of MA patients with a downregulation of FMRP. A potential feedback loop between FMRP and miR-383 during spermatogenesis is proposed, and FMRP acts as a negative regulator of miR-383 functions. Our data also indicate that dysregulation of the FMRP-miR-383 pathway may partially contribute to human spermatogenic failure with MA.

Cell Death and Disease (2013) 4, e617; doi:10.1038/cddis.2013.138; published online 2 May 2013

Subject Category: Experimental Medicine

Spermatogenesis is a tightly regulated process during which spermatogonial stem cells develop into highly differentiated spermatozoa, including spermatogonial proliferation, meiosis of spermatocytes and spermiogenesis of haploid spermatids. ${ }^{1}$ The meiotic and haploid phases of spermatogenesis are characterized by high transcriptional activity but repressed translational activity. Translational repression of mRNAs in these phases must be achieved through a posttranscriptional regulatory mechanism, one of which is mediated by microRNAs (miRNAs). ${ }^{1-3}$ For example, Dicer1 (an RNase III enzyme required for miRNA processing) is required for the proliferation of primordial germ cells and spermatogonia, ${ }^{4}$ spermatid differentiation ${ }^{5}$ and Sertoli cell function and survival; ${ }^{6}$ the deficiency in Drosha (a nuclear RNase III enzyme responsible for cleaving primary miRNAs into precursor miRNAs) leads to disrupted spermatogenesis and male infertility; ${ }^{7}$ the miR-449 cluster and miR-34b/c function redundantly in the regulation of male germ cell development in mice by targeting the E2F-pRb pathway. ${ }^{8}$ On the other hand, we have identified a total of 173 miRNAs, which are expressed differently in testicular tissues of patients with non-obstructive azoospermia (NOA) from control men, including miR-383. ${ }^{9}$ miR-383, predominantly expressed in spermatogonia and primary spermatocytes in both mouse and human testis, is downregulated in NOA patients and promotes testicular embryonal carcinoma cell proliferation by targeting interferon regulatory factor-1 (IRF1). ${ }^{10}$ Our recent study also shows that miR-383 targets to RBMS1 to promote steroidogenesis, and it can be transactivated by steroidogenic factor-1 in somatic granulosa cells during follicular development. ${ }^{11}$ These studies suggest that miRNAs may have critical roles in spermatogenesis and male infertility. However, the regulatory mechanisms of altered miRNA levels and functions still remain elusive.

miRNA biogenesis proceeds from primary miRNA transcripts that are transcribed from the host genome by RNA polymerase II. Primary miRNAs are further processed into mature miRNAs, which are eventually loaded into the RNAinduced silencing complex (RISC), leading to translational repression and mRNA degradation of their targets. ${ }^{3}$ Fragile $X$ mental retardation protein (FMRP) is a functionally important

\footnotetext{
${ }^{1}$ Hefei National Laboratory for Physical Sciences at Microscale and School of Life Sciences, University of Science and Technology of China, Hefei, Anhui 230026, China; ${ }^{2}$ Reproduction Medical Center, Department of Obstetrics and Gynecology, The First Affiliated Hospital of Anhui Medical University, Hefei, Anhui 230032, China; ${ }^{3}$ Department of Urology, The First Affiliated Hospital of Anhui Medical University, Hefei, Anhui 230032, China and ${ }^{4}$ Institute of Neuroscience, The Second Affiliated Hospital of Guangzhou Medical College, Key Laboratory of Neurogenetics and Channelopathies of Guangdong Province and the Ministry of Education of China, Guangzhou 510260, China

${ }^{*}$ Corresponding author: F Sun, Hefei National Laboratory for Physical Sciences at Microscale and School of Life Sciences, University of Science and Technology of China, Huangshan Road, Hefei, Anhui 230026. China. Tel: + 8655163600847 ; Fax: + 86551 63602703; E-mail: feisun@ustc.edu.cn

Keywords: FMRP; miRNA; spermatogenesis

Abbreviations: MA, maturation arrest; NOA, non-obstructive azoospermia; FMRP, fragile X mental retardation protein; NT2, NTERA-2; IRF1, interferon regulatory factor-1; CDK4, cyclin-dependent kinase 4; MAP1B, microtubule-associated protein 1B; Ago, Argonaute; UTR, untranslated region; WT, wild type; MT, mutation type; KO, knockout; IP, immunoprecipitation; dpp, days postpartum; RA, retinoic acid; p-pRb, phosphorylated pRb; NC, negative control

Received 04.2.13; revised 24.3.13; accepted 25.3.13; Edited by A Stephanou.
} 
RNA-binding protein located in the cellular RISC, and controls the level of translation of multiple transcripts. ${ }^{12,13}$ FMRP also interacts with RISC proteins (e.g., Argonaute (Ago) and Dicer) and miRNAs, but it is not essential for RNAi-mediated mRNA cleavage. ${ }^{14-17}$ FMRP expression is widespread but is especially high in the brain and testis. ${ }^{18,19}$ Loss of FMRP in humans causes fragile $X$ syndrome $(\mathrm{FXS}),{ }^{20}$ characterized by autistic behaviors, childhood seizures, abnormal dendritic spines and macroorchidism in male patients. ${ }^{21,22}$ FXS is the only disease that has been linked to the dysfunction of an miRNA pathway thus far, and one hypothesis is that FMRP could affect mRNA translation through interacting with specific miRNAs. ${ }^{16}$ Once binding to its specific mRNA ligands, FMRP may recruit proteins of RISC along with miRNAs and promote the recognition between miRNAs and their target mRNA. ${ }^{16}$ Until now, two miRNAs (miR-125b and miR-132) and their specific mRNA targets (NR2A/B) are reported to be associated with FMRP and subsequently affect dendritic spine morphology. ${ }^{23}$ However, whether FMRP binds to the miRNAs and subsequently functions in mammalian testes remain largely unknown.

In this study, we examined whether miR-383 is regulated by FMRP and the regulatory modes between them during mammalian spermatogenesis.

\section{Results}

FMRP regulates the targeting and functions of miR-383 by interacting with miR-383 and its target mRNAs in vivo and in vitro. As FMRP is highly expressed in the testis, we undertook a specific immunoprecipitation (IP) with purified FMRP from mouse testes to identify FMRP-associated miRNAs. Fmr1 knockout (KO) testes were used as a negative control (NC) for the specificity of miRNA association. Figure 1a confirms that the anti-FMRP antibodies could specifically immunoprecipitate FMRP. As shown in Figure 1b, 88 FMRP-associated miRNAs were identified, including miR-383 (marked in Figure 1b). Among these miRNAs, some were already known to be associated with FMRP in mouse brains, such as miR-132 and miR-125b, ${ }^{23}$ confirming the specificity of our assay. In addition, according to our small RNA deep sequencing results from different types of NOA (spermatogonia arrest, spermatocyte arrest and hypospermatogenesis (unpublished data)), 37 FMRPassociated testicular miRNAs were altered in NOA patients (Supplementary Table S1). These included miR-30c, let-7d* and miR-383, which were downregulated, whereas miR-210, miR-129-3p and miR-24 were upregulated in all three types of NOA (Supplementary Table S1). In addition, RNA-IP and real-time PCR results further confirmed that miR-30a, miR-383, miR-34c*, miR-320 and miR-210 were enriched 2- to 15-fold in FMRP immunoprecipitates from wild-type (WT) testes as compared with control IPs from Fmr1 KO testes (Figure 1c).

The association between FMRP and miR-383 was also validated in vitro. As shown in Figure $2 \mathrm{a}, \mathrm{miR}-383$ was enriched 200-fold in NTERA-2 (NT2) cells. However, unlike the downregulation of miR-383 expression in Fmr $1 \mathrm{KO}$ mouse testes (Figure 1d, Supplementary Figure S1a and Figure 1e), loss of FMRP did not affect the levels of primary and mature
miR-383 in NT2 cells (Supplementary Figure S1b and Figure $2 b$ ); instead, it mediated miR-383 functions, ${ }^{10}$ such as decelerating NT2 cell proliferation (Figure 2c) and inducing G1 cell-cycle arrest (Figure 2d). For example, co-transfection of si-FMRP and the miR-383 mimic into NT2 cells resulted in a significant reduction in cell proliferation (Figure 2c) and a further increase in the G1-phase population (Figure 2d). These results suggest that FMRP-regulated miR-383's effects in NT2 cells are not mediated through alterations in miR-383 levels. Therefore, we ask whether FMRP affects the expression of miR-383 downstream genes.

IRF1 is reported by us to be one of the miR-383's targets. ${ }^{10}$ Cyclin D1 was another potential target of miR-383, as predicted by RNA22 (http://cbcsrv.watson.ibm.com/ rna22.html). The $3^{\prime}$-untranslated region (UTR) of Cyclin D1 mRNA harbors a putative miR-383-binding site, which is evolutionarily conserved in vertebrates (Figure 2e). In addition, the protein and mRNA levels of Cyclin D1 were significantly reduced in miR-383 mimic-transfected NT2 cells, whereas inhibition of endogenous miR-383 enhanced Cyclin D1 protein and mRNA expressions. ${ }^{10}$ In this study, co-transfection of miR-383 dramatically reduced WT Cyclin D1's 3'-UTR reporter activity, whereas inhibition of miR-383 had the opposite effect (Figure 2f). Furthermore, mutation of seed sequences abolished the silencing effects of miR-383 (Figure 2f). These results validated that Cyclin D1 was another direct target of miR-383. Knockdown of FMRP led to significant reductions in the protein levels of miR-383 mimics-mediated downstream genes, including IRF1, Cyclin D1 and cyclin-dependent kinase 4 (CDK4) (Figure 2g), but rescued the protein levels by repression of miR-383 (Figure 2h). Meanwhile, si-FMRP enhanced miR-383mediated downregulation of mRNA levels (Figure $2 \mathrm{i}$ ) and $3^{\prime}$-UTR reporter activities (Figures 2j and k) of IRF1 and Cyclin D1. However, the mutant $3^{\prime}$-UTRs abolished the silencing effects of miR-383 and FMRP (Figures $2 \mathrm{j}$ and $\mathrm{k}$ ). It led us to further determine whether the mRNAs, including IRF1 and Cyclin D1, were specifically associated with FMRP. IP was carried out using purified FMRP from NT2 cells. $\beta$-Actin mRNA was used as an NC for FMRP binding, whereas microtubule-associated protein 1B (MAP1B) mRNA, associated with FMRP in mouse brains, ${ }^{24}$ was used as a positive control. Indeed, the mRNAs of IRF1, Cyclin D1 and MAP1B were co-immunoprecipitated with FMRP (Figure 2l). Taken together, these data indicate that FMRP interacts with miR-383 and its targets IRF1/Cyclin D1 to affect miR-383 targeting to the $3^{\prime}$-UTR of them, and then regulates the miR383's function.

FMRP functions in RISC usually through interacting with Ago proteins, which repress FMRP target genes in an miRNAdependent manner. ${ }^{19,25}$ For example, AGO1, which lacks endonuclease activity but supports translational repression of mismatch-containing miRNA targets, ${ }^{18}$ was reported to regulate the NR2A $3^{\prime}$-UTR in an miR-125-dependent manner. ${ }^{23}$ In this study, si-AGO1 promoted miR-383 mimics-repressed IRF1 and Cyclin D1 3'-UTR reporter activities in HEK293T cells (Figures 2j and k). In addition, double knockdown of FMRP and AGO1 further promoted miR-383's effects (Figures 2j and k). However, the IRF1 and Cyclin D1 $3^{\prime}$-UTR mutation-type (MT) reporters were 
a
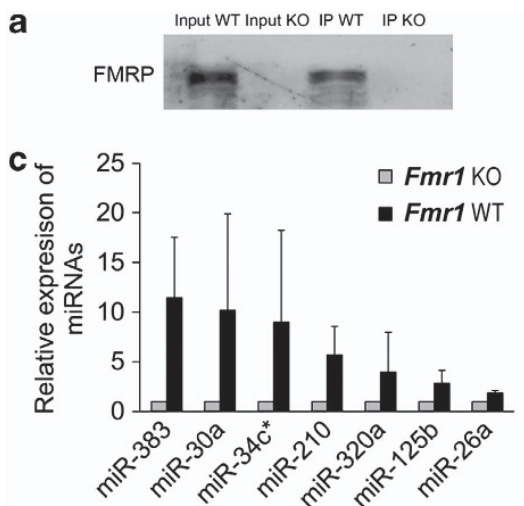

$\left.\begin{array}{ll}\text { b }^{25} \\ \frac{\mathrm{o}}{\mathrm{D}} & 20\end{array}\right]=\begin{aligned} & =\mathrm{Fmr} 1 \mathrm{KO} \\ & =\mathrm{Fmr} 1 \mathrm{WT}\end{aligned}$
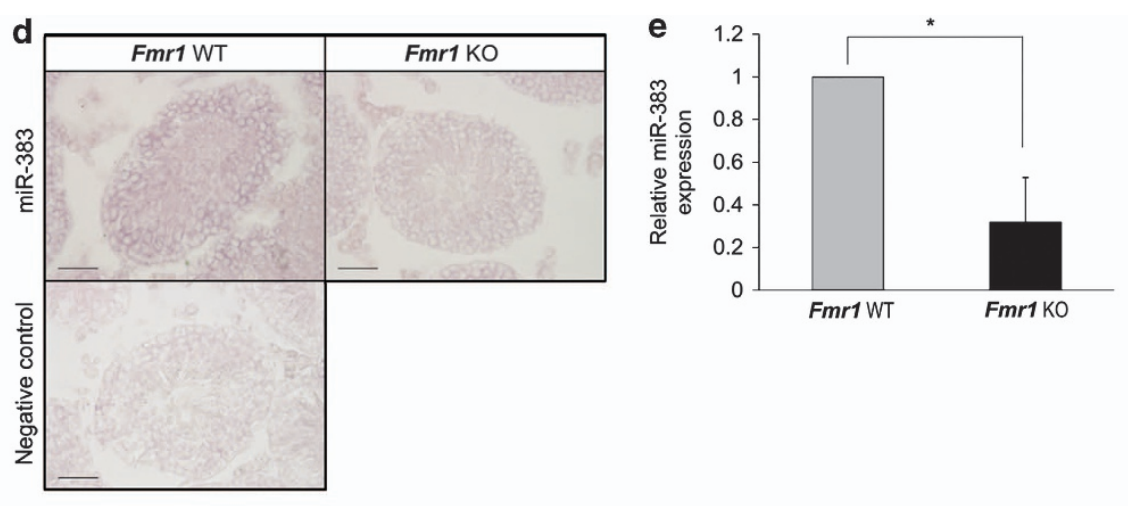

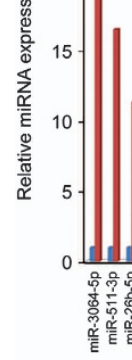

Figure 1 Identification of miRNAs associated with FMRP in mouse testis. (a) Western blotting shows the amount of FMRP in both input and immunoprecipitated FMRPcontaining mRNP complexes from both WT and Fmr1 KO testes. (b) IP of miRNAs with purified FMRP from mouse testes. Identification of copurified miRNAs using the miRCURY LNA Array showed that FMRP binds to 88 miRNAs including miR-383 (marked in barplot). (c) The specific association of miR-30a, miR-383, miR-34c*, miR-320a and miR-210 with FMRP was confirmed by RNA-IP and real-time PCR. (d and e) Both in situ hybridization (panel d) and real-time PCR (panel e) confirmed that miR-383 was reduced in Fmr1 KO mouse testes. Scale bar: $50 \mu \mathrm{m}$. Data are presented as means \pm S.E.M. $(n=3)$. ${ }^{*} P<0.05$

significantly less suppressed by AGO1 knockdown than WT reporters (Figures 2j and k). Real-time PCR and western blotting results also confirmed that AGO1 knockdown further reduced miR-383-mediated downregulation of IRF1 and Cyclin D1 mRNA (Figure 2m) and protein (Figure 2n) levels. Taken together, these data indicate that FMRP as well as AGO1 are involved in the regulation of IRF1 and Cyclin D1 3'UTRs and expression in an miR-383-dependent manner.

FMRP is downregulated by miR-383 via the Cyclin D1-ppRb-E2F1 pathway. Cyclin D1 is indicated to function as a positive regulator of $\mathrm{G} 1$ progression by inactivation of $\mathrm{pRb}^{26}$ and E2F1. ${ }^{27,28}$ In addition, E2F1 can induce FMR1 gene expression in REF52 cells. ${ }^{29}$ We then asked whether FMRP was also regulated by miR-383. The expression levels of components of the RNAi pathway in miR-383 mimicstransfected cells were first examined by real-time PCR. We observed a large decrease in FMRP mRNA and a slight decrease in Dicer, but no obvious changes in DGCR8, Drosha, TRBP and Ago2 (Figure 3a). In addition, miR-383 mimic decreased FMRP protein levels in different cell lines, including NT2 (Figure 3b), GC1(Figure 3c), HeLa (Supplementary Figure S2a) and NIH3T3 (Supplementary Figure S2b), whereas knockdown of miR-383 in NT2 and GC1 cell lines produced the opposite effects (Figures $3 b$ and $\mathrm{c}$ ). Therefore, we speculated that miR-383 might target to FMRP directly. However, miR-383 mimic did not inhibit the reporter activities of FMRP $3^{\prime}$-UTR and coding regions (Supplementary Figure S2c), indicating that FMRP is not a direct target of miR-383. Thus, miR-383 may downregulate FMRP protein levels through miR-383's targets. Indeed, FMRP expression was significantly reduced after knockdown of Cyclin D1 or increased after overexpression of E2F1 in NT2 cells, respectively (Figures $3 d$ and e). Furthermore, the inhibitory effect of FMRP expression by si-Cyclin D1 could be enhanced by miR-383 mimics (Figure $3 f$ ), whereas miR-383 mimics partially rescued the E2F1-induced increases in FMRP at both the protein (Figure $3 g$ ) and mRNA levels (Figure $3 \mathrm{~h}$ ) in NT2 cells. Our data suggest that the Cyclin $\mathrm{D} 1-\mathrm{pRb}-\mathrm{E} 2 \mathrm{~F} 1$ pathway mediates the miR-383-induced downregulation of FMRP expression.

To further validate the Cyclin D1-pRb-E2F1 pathway that mediates miR-383-regulated FMRP expression, pRb phosphorylation levels were examined under retinoic acid (RA) treatment or serum stimulation. RA prevents $\mathrm{pRb}$ phosphorylation in a dose- and time-dependent manner in late $\mathrm{G} 1$ of human B lymphocytes. ${ }^{30}$ Accordingly, different concentrations of RA were added to NT2 (Supplementary Figure S3a) and GC1 (Supplementary Figure S3b) cell cultures for $24 \mathrm{~h}$. The results showed that $10 \mu \mathrm{mol} / \mathrm{l}$ of RA caused considerable inhibition of $\mathrm{pRb}$ phosphorylation and reductions in FMRP protein levels (Supplementary Figures S3a and b), and thus, this concentration was used in the following experiments. Inhibition of miR-383 increased FMRP expression, and 


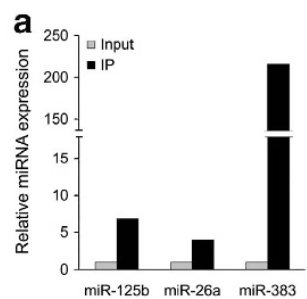

e

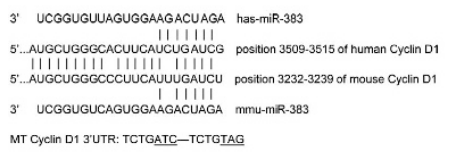

MT Cyclin D1 3'UTR: TCTGATC-TCTGTAG
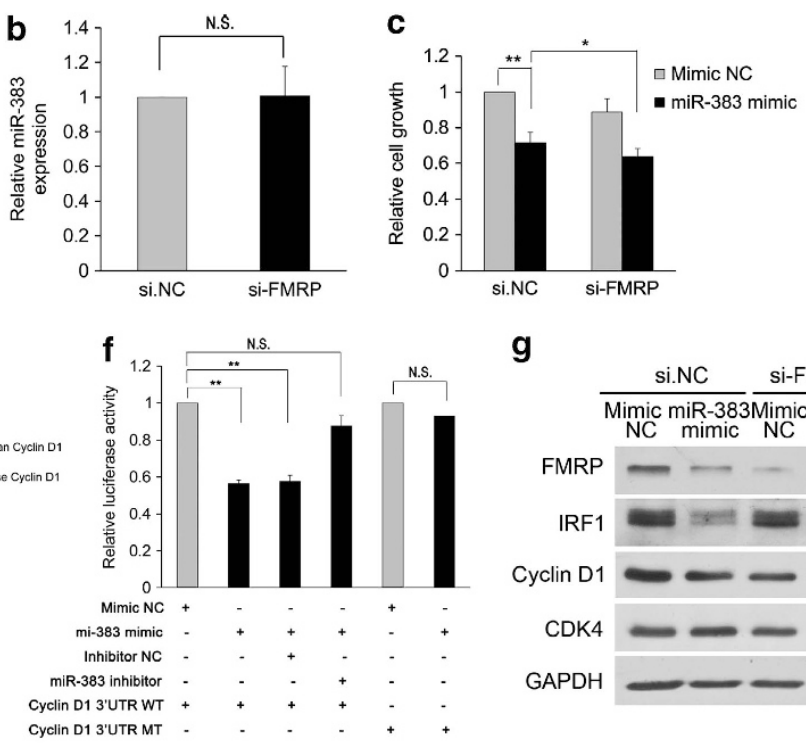

g

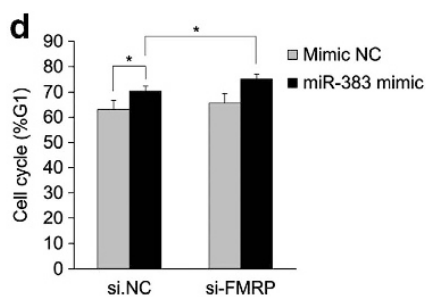

h

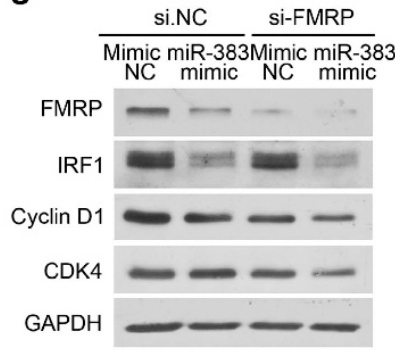

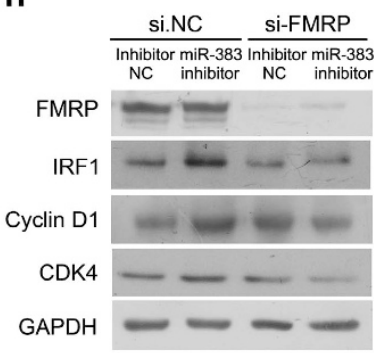

i

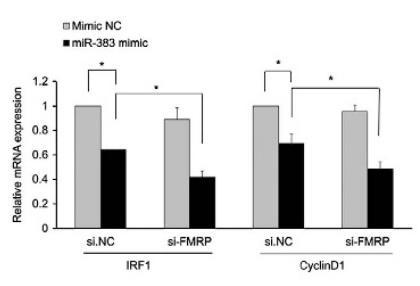

I

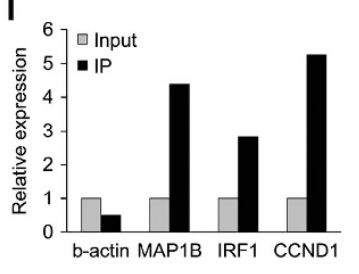

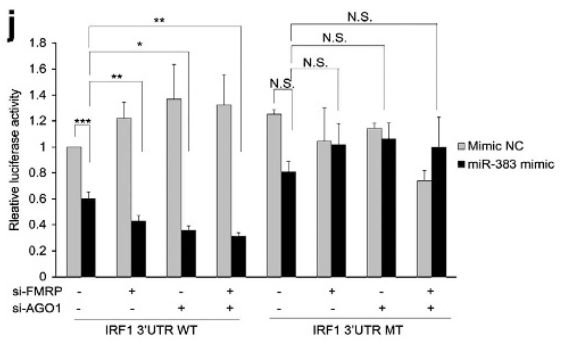

m

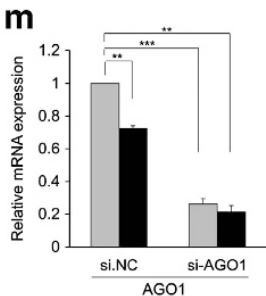

$\square$ Mimic NC

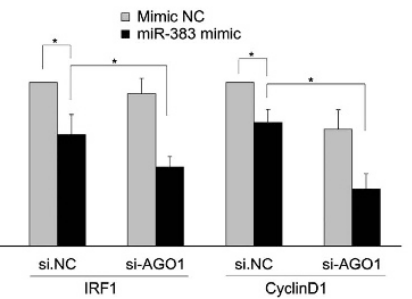

k

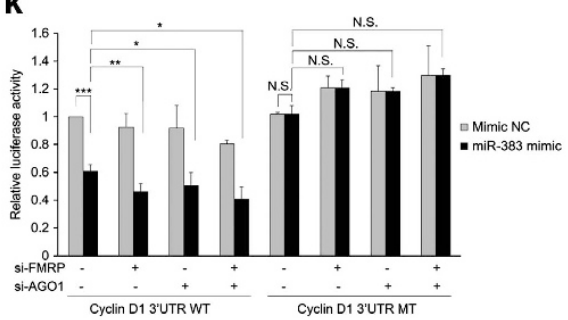

n

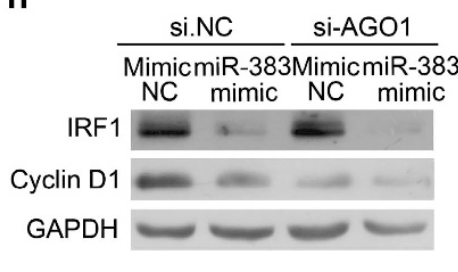

Figure 2 FMRP regulates the expression and function of miR-383 downstream genes by interacting with miR-383 in NT2 cells. (a) Anti-FMRP antibodies could specifically immunoprecipitate miR-383 in NT2 cells. miR-26a was used as NC, whereas miR-125b acted as a positive control. (b) The expression of mature miR-383 did not change significantly. After FMRP knockdown by $50 \mathrm{nM}$ small interfering (si)-FMRP in NT2 cells, miR-383 expression was quantified using TaqMan miRNA assays. (c and d) Silencing of FMRP enhanced miR-383-induced proliferation suppression (panel c) and G1-phase arrest (panel d). (e) Putative-binding sites for human (hsa) miR-383 and mouse (mmu) miR-383 are predicted in the $3^{\prime}$-UTR of Cyclin D1 mRNA. The underlined nucleotides indicate the mutated bases of predicted miR-383-binding sites. WT, wild-type Cyclin D1 3'-UTR; MT, mutation-type Cyclin D1 3'-UTR. (f) miR-383 targeted 3'-UTR of Cyclin D1. Luciferase activity was measured $30 \mathrm{~h}$ after transfection of WT Cyclin D1 3'-UTR or MT Cyclin D1 3'-UTR. ( $\mathbf{g}$ and $\mathbf{~ h}$ ) The loss of FMRP affected miR-383 targeting to its downstream genes. After overexpression or suppression of miR-383 by miR-383 mimic (panel g) or inhibitor (panel h) for $12 \mathrm{~h}$, si.NC or si-FMRP was transfected into NT2 cells for $36 \mathrm{~h}$, and cells were harvested for western blotting. (i) FMRP knockdown enhanced miR-383-mediated downregulation of IRF1 and Cyclin D1 mRNA. miR-383 mimic was transfected into NT2 cells for $12 \mathrm{~h}$, followed by knockdown of FMRP by siRNA for $36 \mathrm{~h}$, and mRNA was extracted for real-time PCR analysis. (j and k) Wild-type IRF1 (panel j) and Cyclin D1 (panel k) 3'-UTR reporter was significantly more reduced by FMRP and/ or AG01 knockdown, whereas mutant $3^{\prime}$-UTRs abolished the silencing effects of miR-383 and FMRP and/or AGO1. FMRP and/or AGO1was knocked down by siRNA in HEK293T cells $12 \mathrm{~h}$ before co-transfection of WT IRF1/Cyclin D1-3'-UTR or MT IRF1/Cyclin D1-3'-UTR with miR-383 mimic or control oligonucleotides. (I) mRNA of IRF1 and Cyclin D1 could be co-immunoprecipitated with FMRP in NT2 cells. $\beta$-Actin and MAP1B were used as NC and positive control, respectively. ( $m$ and $\mathbf{n}$ ) Knockdown of AGO1 also promoted miR-383-mediated downregulation of IRF1 and Cyclin D1 at mRNA (panel m) and protein (panel $n$ ) levels. Data were presented as means \pm S.E.M. for at least three independent experiments, ${ }^{*} P<0.05,{ }^{* \star} P<0.01,{ }^{* \star} P<0.001$, compared with NCs. GAPDH, glyceraldehyde 3-phosphate dehydrogenase; NS, nonsignificant

treatment with RA abolished miR-383-mediated pRb phosphorylation and FMRP upregulation (Figures $4 a$ and b). Enforced expression of miR-383 in both NT2 and GC1 cells (Figures $4 a$ and $b$ ) or knockdown of E2F1 or Cyclin D1 in NT2 cells (Figure 4c) further reduced FMRP levels as induced by RA. As miR-383 inhibits serum-inducible pRb phosphorylation, ${ }^{10}$ we then test whether miR-383 downregulated FMRP through repression of serum-induced phosphorylated $\mathrm{pRb}$ $(p-p R b)$. The results revealed that serum stimulation upregulated FMRP expression in NT2 and GC1 cells (Supplementary Figures S3c and d), and serum-induced FMRP increases were repressed by miR-383 or si-Cyclin D1/E2F1 (Figures 4d and e). Hence, our findings suggested that miR-383 inhibition of FMRP is mediated through altered levels of $\mathrm{pRb}$ 
a

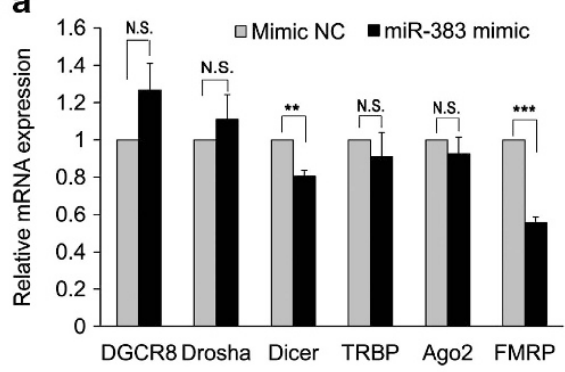

b

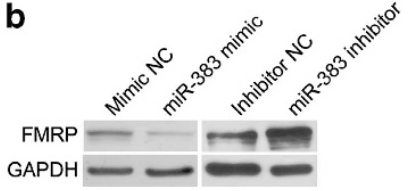

C

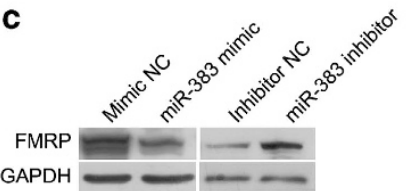

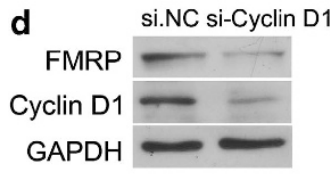
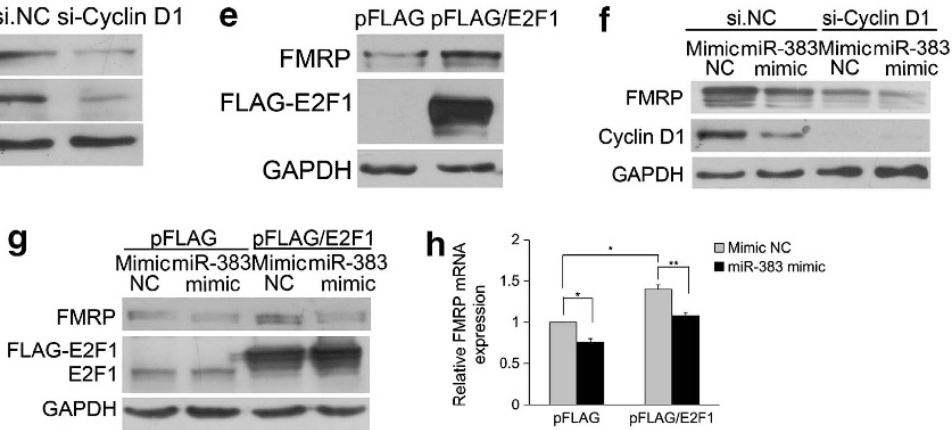

Figure 3 FMRP was downregulated by miR-383 via the Cyclin D1-p-pRb-E2F1 pathway. (a) Real-time polymerase chain reaction (PCR) analysis of DGCR8, Drosha, AGO2, TRBP, Dicer and FMRP in miR-383 mimic-transfected NT2 cells. (b and c) miR-383-reduced FMRP protein expression levels was determined by western blotting in NT2 (panel b) and GC1 (panel c) cells, respectively. NT2 and GC1 cells were transfected with miR-383 mimic (150 nM for NT2 and $100 \mathrm{nM}$ for GC1) or inhibitor (150 nM) for $48 \mathrm{~h}$ and harvested for western blotting. (d) FMRP was reduced after knockdown of Cyclin D1 by RNA interference in NT2 cells. (e) FMRP protein levels were elevated after transfection of pFLAG/E2F1 into NT2 cells compared with control vectors. (f) Cyclin D1 mediation of the miR-383-induced downregulation of FMRP. At $12 \mathrm{~h}$ after transfection with $150 \mathrm{nM}$ miR-383 mimic, cells were further transfected with $50 \mathrm{nM}$ small interfering (si)-Cyclin D1 for $36 \mathrm{~h}$ and harvested for western blotting analysis. ( $\mathrm{g}$ and $\mathbf{h}$ ) The $\mathrm{pRb}-\mathrm{E} 2 \mathrm{~F} 1$ pathway mediated the regulation of miR-383-FMRP in NT2 cells. After overexpression of miR-383 mimic for $12 \mathrm{~h}$, an E2F1 expression vector (pFLAG/E2F1) was transfected for $36 \mathrm{~h}$, and NT2 cells were harvested for both immunoblot analysis (panel g) and real-time PCR detection (panel $\mathrm{h}$ ). Data were presented as means \pm S.E.M. for at least three independent experiments. ${ }^{*} P<0.05,{ }^{* \star} P<0.01$, ${ }^{* \star *} P<0.001$, compared with NCs. GAPDH, glyceraldehyde 3-phosphate dehydrogenase; NS, nonsignificant
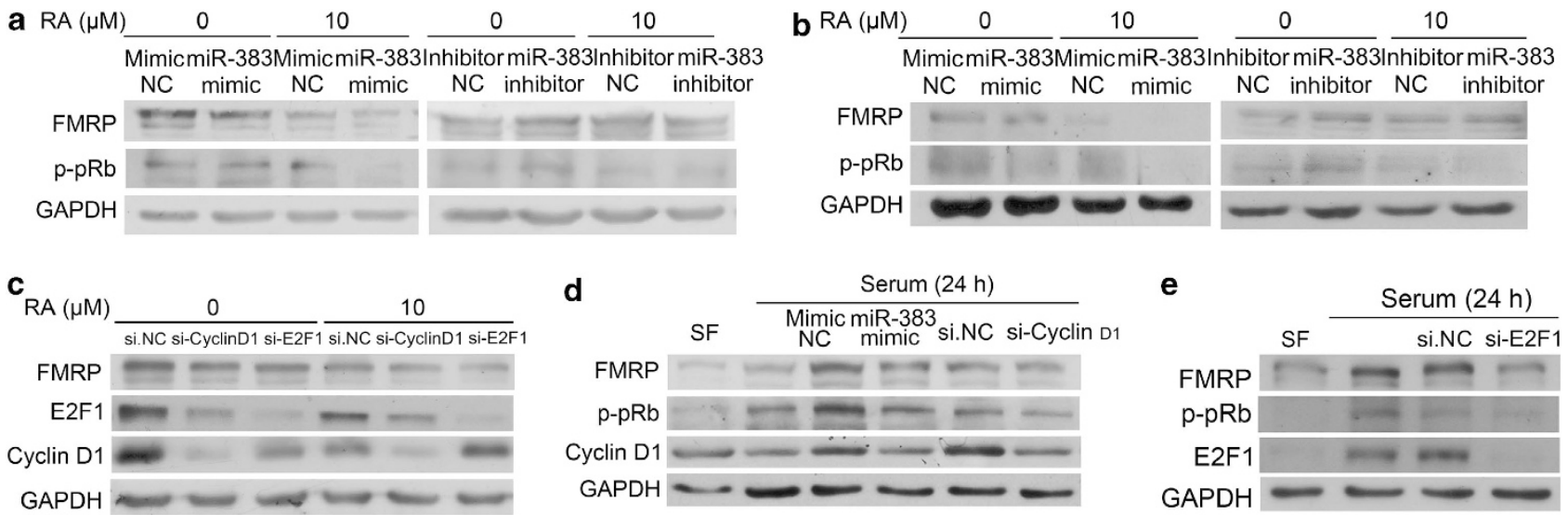

Figure 4 Altered levels of $\mathrm{pRb}$ phosphorylation by RA or serum stimulation can mediate miR-383-regulated inhibition of FMRP. (a and $\mathbf{b}$ ) Treatment of RA abolished miR-383-mediated pRb phosphorylation and FMRP upregulation. Both NT2 (panel a) and GC1 (panel b) cells were transfected with $150 \mathrm{nM}$ miR-383 mimic or inhibitor, followed by treatment with $10 \mu \mathrm{M}$ RA or dimethylsulfoxide for $24 \mathrm{~h}$. Protein levels of FMRP and p-pRb were detected by western blotting. (c) Cyclin D1 and E2F1 contributed to RA-induced increased FMRP levels. Cyclin D1 or E2F1 was knocked down by small interfering RNAs (siRNAs) in NT2 cells $24 \mathrm{~h}$ before $10 \mu \mathrm{M}$ RA treatments, and cells were harvested for immunoblot. (d and e) Serum-induced FMRP elevation was repressed by miR-383 (panel d) or si-Cyclin D1/E2F1 (panel e). NT2 and GC1 cells were synchronized by serum starvation, transfected with miR-383 or si-Cyclin D1/si-E2F1, and induced to re-enter the cell cycle by the addition of serum. For western blotting analysis, cells were harvested $24 \mathrm{~h}$ after serum stimulation of growth-arrested cells.

phosphorylation. Taken together, these results indicate that FMRP, which acts as a negative regulator of miR-383 function, is feedback regulated by miR-383 through the Cyclin D1-p-pRb-E2F1 pathway.
Dysregulation of FMRP-miR-383 regulatory pathways in testes of Fmr1 KO mice and of patients with maturation arrest. To validate whether the feedback loop between FMRP and miR-383 also exists during spermatogenesis, the 


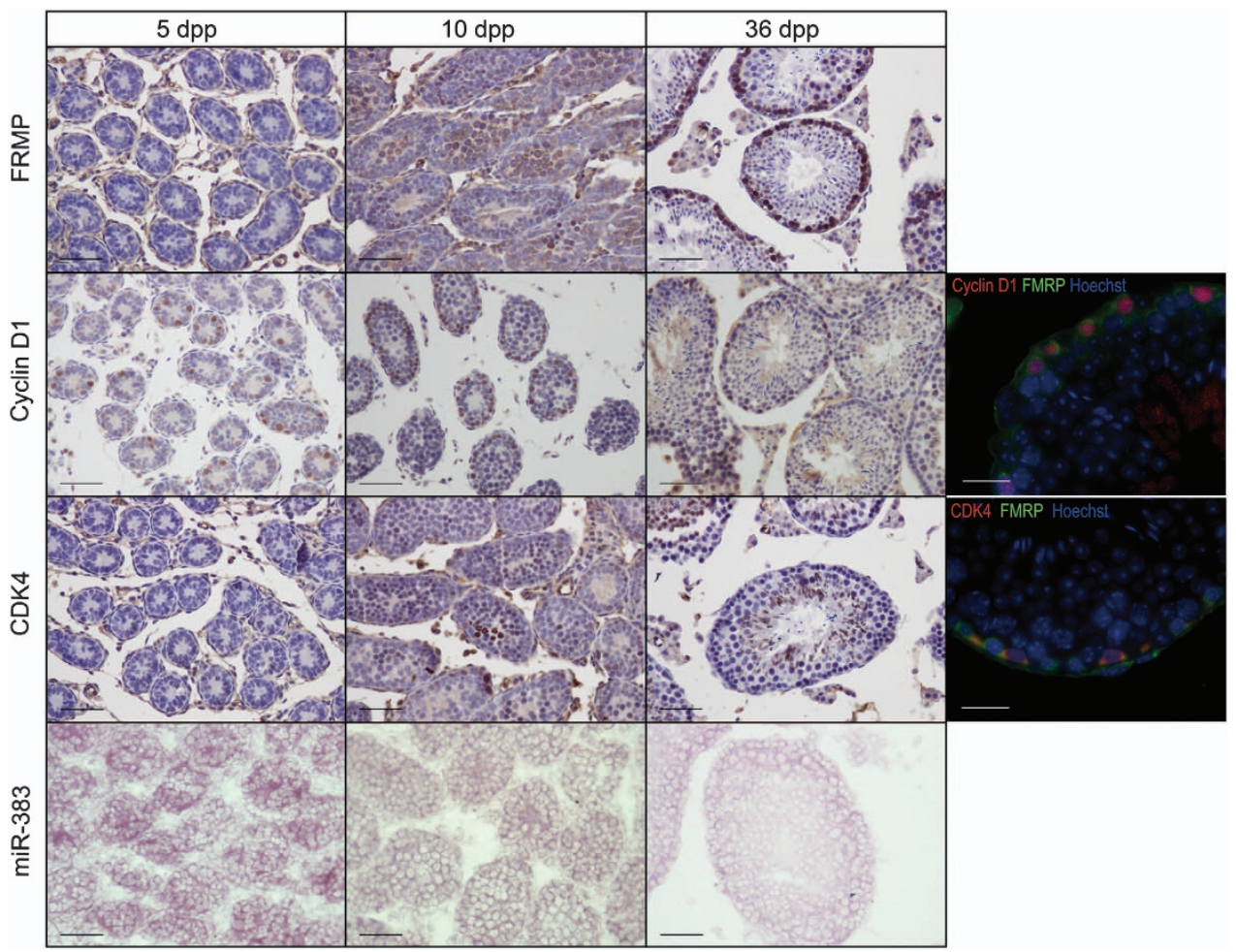

Figure 5 Immunohistochemical and immunofluorescence staining for indicated proteins in the mouse testes during postnatal development (5, 10 and $36 \mathrm{dpp})$. Immunofluorescence showed the colocalization of Cyclin D1/CDK4 (red) and FMRP (green) in spermatogonia. Nuclei were stained with Hoechst and shown in blue. Scale bar: $50 \mu \mathrm{m}$ for 40 -fold and $13 \mu \mathrm{m}$ for 100 -fold

expression of FMRP, miR-383 and its targets were first investigated in mouse testis during postnatal development. ISH analysis showed that miR-383 was highly expressed in spermatogonia from 5 days postpartum (dpp), and the expression was also detected in primary spermatocytes as we reported previously (Figure 5 ). ${ }^{10}$ FMRP was not detected at $5 \mathrm{dpp}$ but started to show positive signals from $10 \mathrm{dpp}$, and was predominantly expressed in spermatogonia. The expression of Cyclin D1 was detected in type A spermatogonia during postnatal development. CDK4 was also mainly expressed in spermatogonia. However, an aggregated expression pattern of CDK4 was observed in spermatocytes of $10 \mathrm{dpp}$ mouse testis, and this aggregated expression disappeared in adult mouse testis (Figure 5). Immunofluorescence results further confirmed the colocalization of Cyclin D1/CDK4 and FMRP in spermatogonia (Figure 5). These observations corroborate that FMRP, miR-383 and its downstream genes, including IRF1, ${ }^{10}$ Cyclin D1 and CDK4, shared a similar expression pattern in mouse testis. Therefore, it was possible that the similar regulation pathways measured in vitro might exist during spermatogenesis.

RNA-IP of mouse testis also confirmed that IRF1, Cyclin D1 and CDK4 mRNA exhibited 4.1-, 2.7- and 1.5-fold enrichment in the FMRP mRNPs, respectively (Figure 6a). Although there was no significant change in mRNA levels (Figure 6b), the loss of FMRP in the testis led to higher IRF1, Cyclin D1 and CDK4 protein levels (Figure 6c). Immunohistochemistry results showed that in Fmr1 KO testes, there was no noteworthy alteration in the expression patterns of IRF1 and Cyclin D1, but CDK4 localization was dysregulated (Figure 6d).
Normally, CDK4 was predominantly expressed in the nuclei and cytoplasm of type A spermatogonia, ${ }^{31}$ and the CDK4 foci were also detected along the synapsed axes in leptotene and zygotene spermatocytes (marked by $\gamma \mathrm{H} 2 \mathrm{AX}$ ) (Figure 6e). ${ }^{31,32}$ In Fmr1 KO testes, CDK4 was not colocalized with $\gamma \mathrm{H} 2 \mathrm{AX}$, but accumulated in the division phase of metaphase spermatocytes (Figures $6 \mathrm{~d}$ and e). The mislocation of CDK4 was also observed in the testis of maturation arrest (MA) patients. ${ }^{10}$ These results indicated that loss of FMRP led to CDK4's aggregation in the division phase of primary spermatocytes, and thus may affect meiosis. However, there was no significant alteration in MLH1 meiotic recombination foci on synapsed chromatin in Fmr1 KO meiocytes (Supplementary Figure S4).

Increased DNA damage was also observed in the testes of Fmr1 KO mice. For example, Rad51 (a DNA damage sensor) ${ }^{33}$ was only observed in spermatocytes near the basement membrane of the Fmr1 WT tubules, and also detected in cells within the lumen of Fmr1 KO tubules (Figure 6f); $\gamma \mathrm{H} 2 \mathrm{AX}$ was concentrated in the $\mathrm{XY}$ body of pachytene spermatocyte ${ }^{34}$ in Fmr1 WT testis (Figure 6f), but many Fmr1 KO spermatocytes exhibited diffuse staining for $\gamma \mathrm{H} 2 \mathrm{AX}$. In addition, the $\gamma \mathrm{H} 2 \mathrm{AX}$ signal was detected on the autosomes of Fmr1 KO meiocytes (Supplementary Figure S4). However, the protein levels of $\gamma \mathrm{H} 2 \mathrm{AX}$ were not different between Fmr1 WT and KO testis (Figure 6g), while p53, an important protein that appears to sense multiple types of DNA damage, ${ }^{35}$ was significantly upregulated in testes of Fmr1 KO mice (Figure 6g). Moreover, positive TUNEL staining (upper panel of Figure $5 \mathrm{~h}$ ) in spermatocytes of 

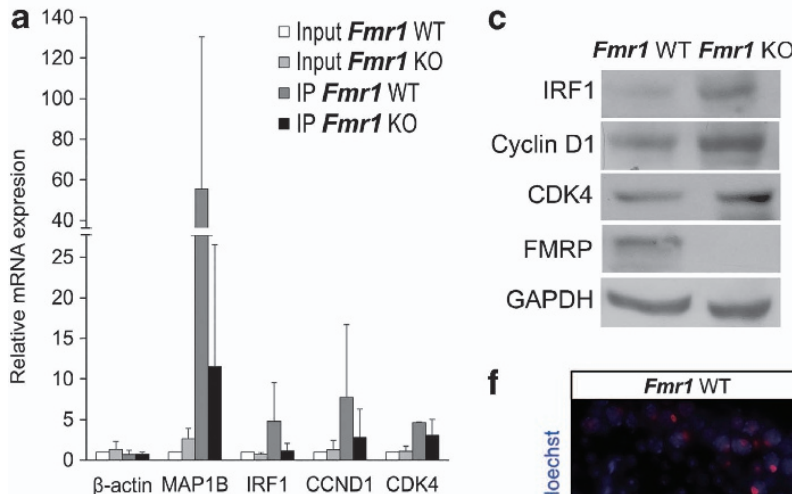

g

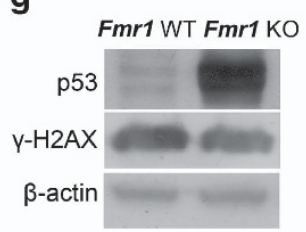

f

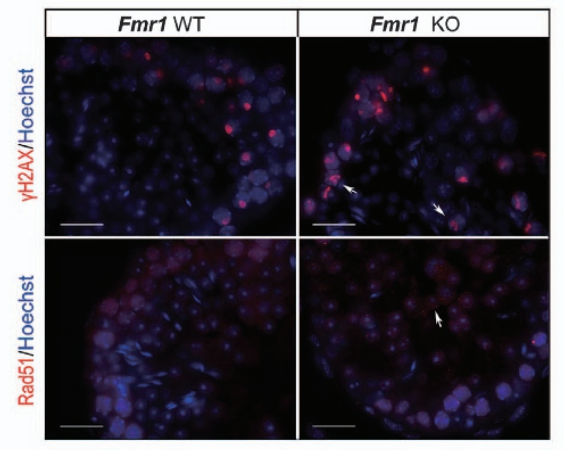

CDK4

Merged

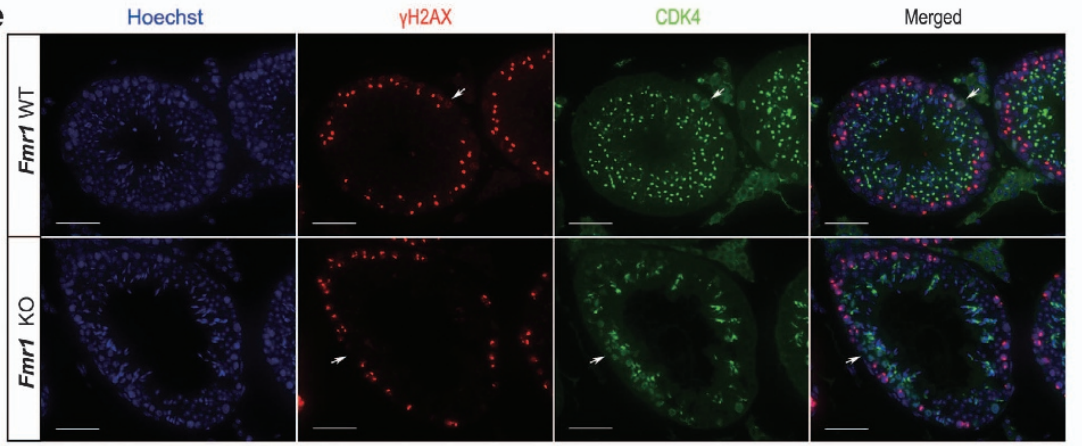

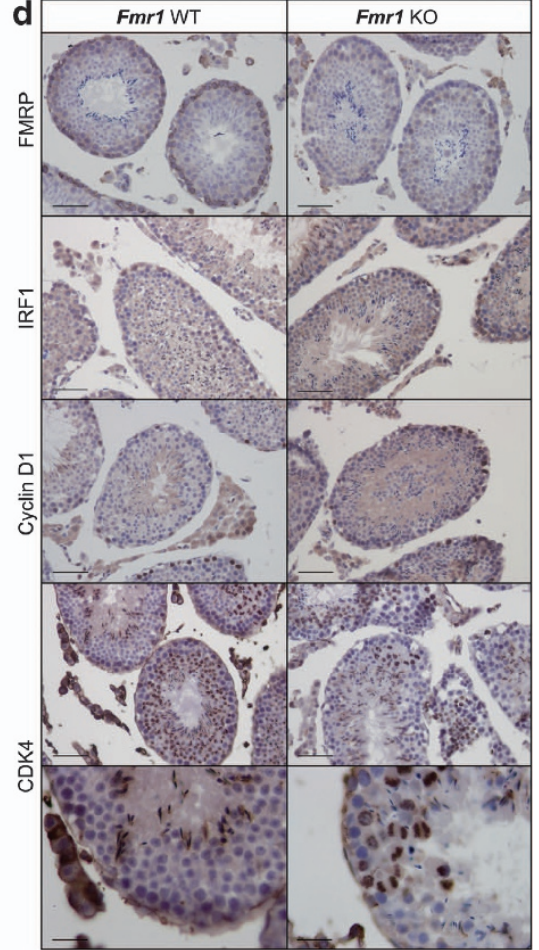
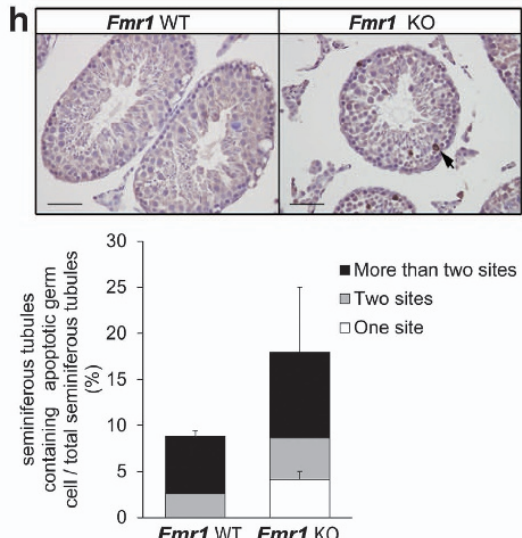

Figure 6 FMRP interacts with miR-383 downstream genes in mouse testis, and CDK4 is dysregulated in Fmr1 KO testis. (a) mRNA of IRF1, Cyclin D1 and CDK4 could be co-immunoprecipitated with FMRP in mouse testes. The RNAs from input and co-IP assays, using anti-FMRP antibody and Fmr1 WT and KO mouse testes, were isolated and subjected to real-time polymerase chain reaction (PCR). $\beta$-Actin and MAP1B were used as a NC and positive control, respectively. (b and $\mathbf{c}$ ) The mRNA (panel b) and protein (panel c) expression levels of IRF1, Cyclin D1 and CDK4 were measured by real-time PCR and western blotting in both WT and Fmr1 KO mouse testes, respectively. Glyceraldehyde 3-phosphate dehydrogenase was used as a loading control. Data are presented as means \pm S.E.M. $(n=3)$. (d) The expression patterns of IRF1, Cyclin D1 and CDK4 were analyzed by immunohistochemical staining. Arrowheads indicate aggregation of CDK4 in primary spermatocytes. Scale bar: $50 \mu \mathrm{m}$ for 40 -fold and $13 \mu \mathrm{m}$ for 100 -fold. (e) The immunofluorescence showed CDK4 accumulation in the division phase of primary spermatocytes. $\gamma \mathrm{H} 2 \mathrm{AX}$ was used as a marker of zygotene to pachytene stages. Arrowheads indicate positive signals of CDK4. Blue, Hoechst; red, $\gamma \mathrm{H} 2 \mathrm{AX}$; green, CDK4. Scale bar: $50 \mu \mathrm{m}$. (f) The expression patterns of Rad51 and $\gamma \mathrm{H} 2 \mathrm{AX}$ were analyzed by immunofluorescence staining. Arrowheads indicate abnormal Rad51 and $\gamma \mathrm{H} 2 \mathrm{AX}$ staining in Fmr1 KO testes. Scale bar: $13 \mu \mathrm{m}$. (g) DNA repair complex protein expression was analyzed by western blot in both WT and Fmr1 KO mouse testes. (h) Apoptotic germ cells (upper panel) and apoptotic rates (lower panel) in Fmr1 WT and KO testis were identified by terminal deoxynucleotidyl transferase dUTP nick-end labeling (TUNEL) assays. Arrowheads indicate TUNEL-positive cells. Scale bar: $50 \mu \mathrm{m}$

Fmr1 KO testes was slightly upregulated compared with that of WT testes (lower panel of Figure 6h). Taken together, loss of FMRP may promote DNA damage in meiotic cells and trigger apoptosis in spermatocytes.

The expression patterns of FMRP, PCNA (marked for proliferating spermatogonia in the testis) ${ }^{36}$ and miR-383 were also analyzed in testicular specimens of MA and hypospermatogenesis patients by immunohistochemistry and real-time analysis. The immunohistochemical expression pattern of FMRP and PCNA is summarized in Table 1. In the germ cells in four normal controls and in four out of five hypospermatogenesis patients, FMRP expression was detected in the cytoplasm of spermatogonia. The strong spermatogonial staining was also confirmed by the Human Proteinatlas (http://www.proteinatlas.org/ENSG00000102081/normal/testis). Although the positive PCNA staining was detected in all groups, FMRP was almost 
undetectable in the seminiferous tubules of nine out of $14 \mathrm{MA}$ patients (Figure $7 a$ and Table 1). Furthermore, FMRP mRNA was remarkably downregulated in patients with MA, but was not significantly altered in patients with hypospermatogenesis (Figure 7b). PCNA mRNA levels remained unchanged in the testicular tissues of control men and of MA patients (Figure 7c). The expression of miR-383 was also significantly reduced in nine MA testes with no significant change in eight hypospermatogenesis testes compared with four normal controls (Figure 7d). These results indicate that dysregulation of the FMRP-miR-383 pathway may contribute to human spermatogenic failure.

Table 1 Expression of FMRP and PCNA in human testicular specimens

\begin{tabular}{|c|c|c|c|}
\hline & $\begin{array}{l}\text { Normal } \\
\text { control }\end{array}$ & $\begin{array}{l}\text { Hypospermato- } \\
\text { genesis }\end{array}$ & $\begin{array}{l}\text { Maturation } \\
\text { arrest }\end{array}$ \\
\hline Number & 4 & 5 & 14 \\
\hline $\begin{array}{l}\text { FMRP } \\
\text { detected }\end{array}$ & 4 & 4 & 5 \\
\hline $\begin{array}{l}\text { PCNA } \\
\text { detected }\end{array}$ & 4 & 5 & 14 \\
\hline
\end{tabular}

Expressions of FMRP and PCNA proteins were determined by immunohistochemical analysis. FMRP was detected in four out of five in the testis of hypospermatogenesis patients, but it was almost undetectable in the seminiferous tubules of 9 out of 14 MA patients. Positive PCNA staining was detected in all groups

\section{Discussion}

In this study, we identified 88 FMRP-associated miRNAs in mouse testis, including a specific set of miRNAs such as miR383 , which are altered in testes of patients with NOA. FMRP is also associated with miR-383's target mRNAs, including IRF1 and Cyclin D1, affecting miR-383 binding to the $3^{\prime}$-UTR of IRF1 and Cyclin D1, and subsequently their expression. Knockdown of endogenous FMRP promotes miR-383mediated effects on the cell cycle and on proliferation. On the other hand, miR-383 decreases FMRP levels via inhibition of the Cyclin D1-p-pRb-E2F1 pathway in both NT2 and GC1 cells (Figure 8). Furthermore, loss of FMRP in mouse testis is associated with reduced miR-383 expression, dysregulation of CDK4 expression and more DNA damages. Also, both FMRP and miR-383 were reduced remarkably in the testis of MA patients. Therefore, our data support a model in which FMRP acts as a negative regulator of $\mathrm{miR}-383$ functions and a potential feedback loop is constructed between miR-383 and FMRP during spermatogenesis (Figure 8).

MiR-383, one of the most downregulated miRNAs in NOA patients, has a critical role during spermatogenesis. ${ }^{10}$ Further understanding the regulating factors and mechanism for miR383 expression in infertile men will help us to uncover the reasons or pathways of spermatogenesis failure. In this study, we found that FMRP regulated miR-383 targeting and

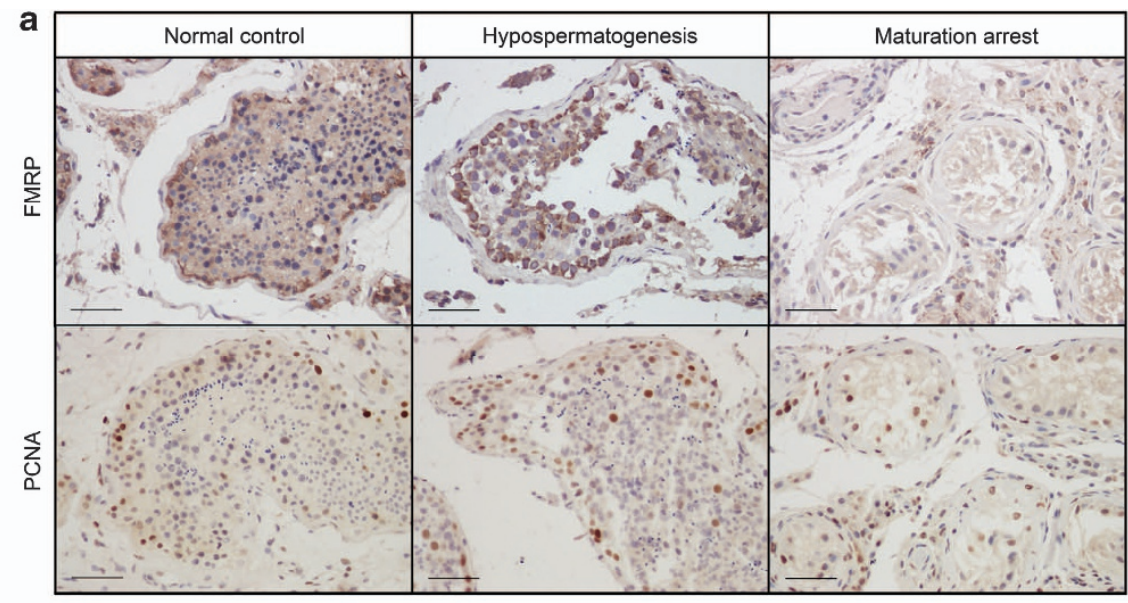

b

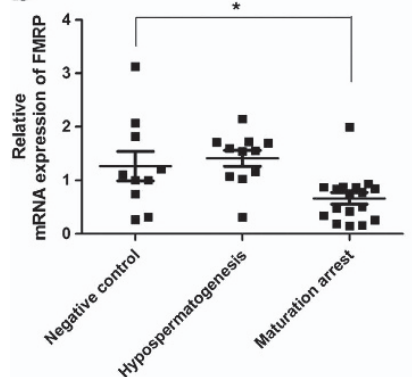

C

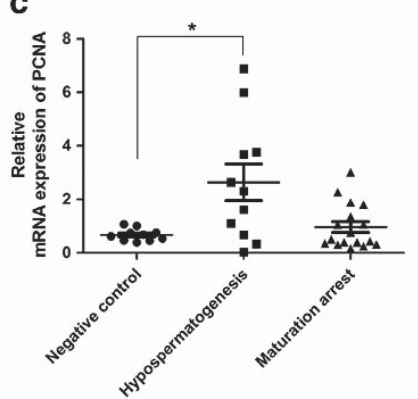

d

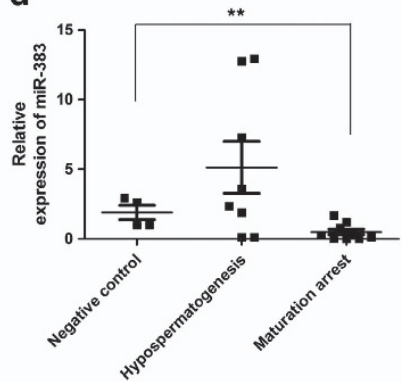

Figure7 Expression of FMRP, proliferating cell nuclear antigen (PCNA) and miR-383 in control and MA patients. (a) Immunohistochemical analysis for FMRP and PCNA in the testes of normal controls, hypospermatogenesis and MA patients. Scale bar: $50 \mu \mathrm{m}$. (b and c) Expression levels of FMRP (panel b) and PCNA (panel c) in the testes of normal controls $(n=10)$, hypospermatogenesis $(n=11)$ and MA patients $(n=17)$ were measured by real-time polymerase chain reaction (PCR) in triplicate. (d) Expression levels of miR-383 in the testes of normal controls $(n=4)$, hypospermatogenesis $(n=8)$ and MA patients $(n=9)$ were measured by real-time PCR in triplicate. ${ }^{*} P<0.05$, ${ }^{\star *} P<0.01$, compared with negative controls 


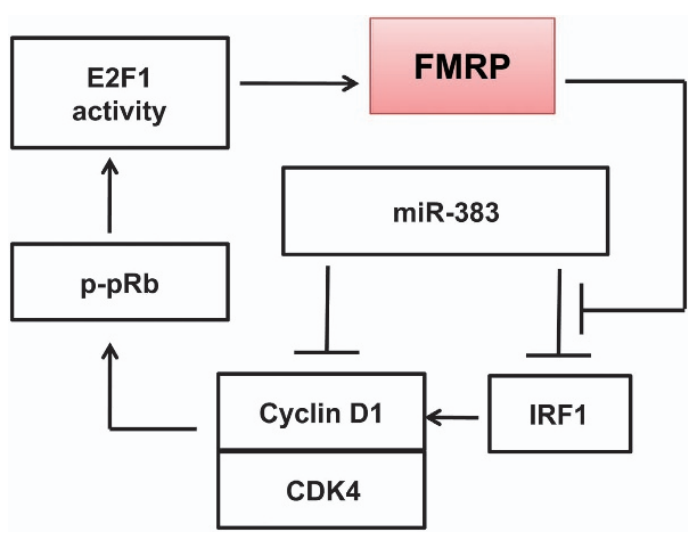

Figure 8 Model of FMRP functions during spermatogenesis. FMRP was downregulated by overexpression of miR-383 in NT2 and GC1 cells via the miR-383-Cyclin D1-p-pRb-E2F1 pathway. FMRP was associated with miR-383 and the mRNAs of its targets including IRF1, Cyclin D1 and CDK4, affecting miR-383-induced suppression of cell proliferation in NT2 cells and spermatogenesis in Fmr1 $\mathrm{KO}$ testis

functions by interacting with mature miR-383 both in vivo and in vitro. As an RNA-binding protein, FMRP has an important role in regulating the level of translation of multiple transcripts. ${ }^{12,13}$ So far, FMRP-associated specific miRNAs had only been identified by FMRP immunoprecipitates from fly ovaries and mouse brains. ${ }^{23,37}$ In this study, we have identified 88 FMRP-associated miRNAs in mouse testis, including miR-320, which is one of the most abundantly expressed miRNAs in mouse testis; ${ }^{38}$ miR-214 and miR-36, which are significantly overexpressed in sexually immature mouse testis; ${ }^{39}$ and miR-361, which is a type I X-linked miRNA expressed in premeiotic spermatogonia, followed by decreased expression in spermatocytes and spermatids. ${ }^{40}$ In addition, we visualize that the regulation of miR-383 targets by FMRP is miR-383 dependent in vivo. First, FMRP knockdown does not significantly affect miR-383 and its target mRNA or protein levels. However, knockdown of FMRP in miR-383-overexpressing NT2 cells is associated with further reductions in IRF1 and Cyclin D1 levels. Second, mutated miR-383 target sites from the IRF1 and Cyclin D1 $3^{\prime}$-UTRs dampen the regulation of the latter by FMRP, implying that the regulation of IRF1 and Cyclin D1 by FMRP is in an miR-383dependent manner. Furthermore, the miR-383-mediated IRF1 and Cyclin D1 levels were usually regulated by FMRP as well as by AGO1. However, our data cannot reveal whether miRNAs associate with FMRP directly or indirectly, nor how FMRP and Ago guide specific miRNAs onto target mRNAs. Thus, further work is needed to uncover how FMRP regulates the translation of target mRNAs using miRNAs.

For the first time, we report that FMRP is downregulated in the testis of MA patients. In addition, according to our small RNA deep sequencing results from different types of NOA, among the identified FMRP-associated miRNAs, 37 miRNAs were altered in testes of NOA patients, including the downregulated $\mathrm{miR}-383$ and $\mathrm{miR}-30 \mathrm{c}$ (inhibiting mitochondrial fission and the consequent apoptosis through targeting p53) $;{ }^{41}$ the upregulated miR-210 (having a role in the cellular hypoxia response) ${ }^{42,43}$ and miR-24 (having a p53- independent, antiproliferative effect by targeting E2F2 and Myc). ${ }^{44,45}$ These data suggest that dysregulation of FMRP and FMRP-associated miRNAs may contribute to male infertility.

On the other hand, miR-383 also regulated FMRP levels through affecting the $p-p R b-E 2 F 1$ pathway. E2F1 expression promotes $\mathrm{G} 1$-to-S phase progression in mammalian cells by activating genes involved in DNA replication and cell-cycle control. ${ }^{46}$ In our recent study, miR-383 inhibited the expression of c-Myc via targeting to its transcription factor RBMS1 directly to promote estradiol release from granulosa cells. ${ }^{11}$ Expression of the E2F1 gene is known to be induced by c-Myc. ${ }^{47,48} c-M y c$ expression is also induced by E2F1, revealing a putative positive-feedback circuit. ${ }^{49}$ In addition, the FMR1 gene is the most prominent candidate gene in premature ovarian failure, ${ }^{50}$ and $F M R 1$ expression during human folliculogenesis is probably a quantitative trait, which affects the process of folliculogenesis. ${ }^{51}$ Therefore, the miR-383-mediated Cyclin D1-E2F1-FMRP pathway and c-Myc may establish a feedback network contributing to folliculogenesis and hormone release.

The feedback regulation between FMRP and miR-383 is validated in spermatogenic failure. For example, both FMRP and miR-383 were downregulated in NOA patients. Furthermore, loss of FMRP-reduced miR-383 expression and function because of the loss of interactions with mature miR-383 in Fmr1 KO testis. Correspondingly, the genes downstream of miR-383, including IRF1, Cyclin D1 and CDK4, are upregulated in Fmr1 $\mathrm{KO}$ testis as well as in the testis of MA patients. ${ }^{10}$ IRF1, which promotes germ cell survival in vitro and in vivo, functions as a promitogenic factor in spermatogonia. ${ }^{10}$ Most MA patients showed significantly higher IRF1 expression in the nucleus of both spermatogonia and/or primary spermatocytes. ${ }^{10}$ Cyclin D1, an important factor in the G1/S-phase transition, showed a significant nuclear expression pattern in MA patients, ${ }^{10}$ while it is not detected in normal adult human male germ cells. ${ }^{52}$ CDK4, another positive regulator of G1 progression, mediates the effect of miR-383 on pRb phosphorylation in the human testis, where widespread expression of $p-p R b$ is observed in the testes of infertile men. ${ }^{10}$ Normally, CDK4 was mainly expressed in the nuclei and cytoplasm of type A spermatogonia. ${ }^{31}$ However, CDK4 expression accumulated in the nucleus of primary spermatocytes in the testis of MA patients ${ }^{10}$ and of Fmr1 KO mice. Therefore, FMRP-associated IRF1 and Cyclin D1 upregulation, as well as FMRP-miR-383-regulated CDK4, may contribute to spermatogenesis failure in human testis. DNA damage in meiotic cells and apoptotic spermatocytes are also observed in Fmr1 KO testes, which may prevent sperm from maturing. ${ }^{53}$ Thus, although $F m r 1 \mathrm{KO}$ mice can have offspring, it also led us to further reveal whether FMRP-miR-383 double downregulation in human testis may affect spermatogenesis.

In summary, we propose a potential feedback loop in which FMRP interacts with miR-383, affecting expression of its downstream genes, and miR-383 downregulates FMRP through targeting Cyclin D1. Our data suggest a dysregulated FMRP-miR-383 pathway during spermatogenic arrest. The mechanistic studies regarding the role of miRNA-protein interactions during spermatogenesis will provide new clues to treating male infertility. 


\section{Materials and Methods}

Antibodies. FMRP monoclonal antibody for RNA-IP was kindly provided by Dr. Stephen T Warren and Dr. Peng Jin (Emory University, Atlanta, GA, USA). Rabbit polyclonal antibodies to IRF1, Cyclin D1, E2F1, Rb (pSpT249/252) phospho-specific antibody, $\gamma \mathrm{H} 2 \mathrm{AX}, \mathrm{MLH} 1, \mathrm{Rad} 51$ and $\beta$-actin were purchased from Santa Cruz Biotechnology Inc. (Dallas, TX, USA), Cell Signaling Technology (Danvers, MA, USA), Abcam (Cambridge, MA, USA) and Oncogene (Darmstadt, Germany). Mouse antibodies to FMRP, CDK4, synaptonemal complex protein 3, p53, PCNA and GAPDH were purchased from Millipore (Billerica, MA, USA), Abcam and Santa Cruz Biotechnology Inc.

Mice and human testicular samples. ICR mice were obtained from the Animal Center, University of Science and Technology of China (USTC, Hefei, China). Fmr1 KO mice ${ }^{54}$ in FVB background were obtained from the Institute of Neuroscience, the Second Affiliated Hospital of Guangzhou Medical University (Guangzhou, China). All animal experiments were carried out according to the guidelines for the care and use of laboratory animals from USTC.

For human testicular samples, biopsy specimens from 40 patients with NOA (16 patients with hypospermatogenesis (ages 24-34 years) and 24 patients with MA (ages 20-44 years)) and 12 normal controls (ages 24-43 years) were obtained from the First Affiliated Hospital of Anhui Medical University (Hefei, China). As normal controls, the study population consists of obstructive azoospermia with normal spermatogenesis. All patients had at least two semen analyses showing azoospermia. Testicular specimens were collected and divided into several portions for different experiments. All patients gave informed consent and the research received ethical approval from the institutional review boards of the USTC and the Anhui Medical University.

DNA constructs. psiCHECK-2 dual luciferase reporter vector was kindly provided by Biliang Zhang (Guangzhou Institute of Biomedicine and Health, Chinese Academy of Sciences, Guangzhou, China) and the p3XFLAG-myc-CMV24 expression vector was provided by Mian Wu (School of Life Sciences, USTC). The vector expressing the E2F1protein was constructed by cloning human E2F1 cDNAs into the p3XFLAG-myc-CMV-24 vector. $3^{\prime}$-UTR fragments of putative miRNA targets (Supplementary Table S2) were cloned into the psiCHECK-2 vector (Promega, Madison, WI, USA).

siRNA duplexes homologous in sequence with the miRNA-383 mimic and miR-383 inhibitor, as well as a scrambled NC, were synthesized and purified by the Shanghai Gene-Pharma Co. (Shanghai, China). The miR-383 inhibitor is 2'-OMe-modified single-stranded nucleic acids antisense to their target miRNAs. siRNA (si-FMRP, si-cyclin D1, si-CDK4, si-E2F1 and si-Ago1) were all supplied from Santa Cruz Biotechnology Inc. For ISH assays, $5^{\prime}$-end digoxigenin-labeled locked nucleic acid (LNA)-modified DNA oligonucleotides complementary to mature miR-383 (LNA miR-383) and scrambled NCs (LNA scrambled) were obtained by Exiqon A/S (Vedbaek, Denmark). Oligonucleotide sequences are provided in Supplementary Table S3.

\section{FMRP-IP, RNA extraction, reverse transcription and quantitative} PCR. mRNAs were extracted from cell lines and human testes with SV Total RNA Isolation System (Promega; Z3100) or mirVana miRNA isolation kit (Applied Biosystems, Foster City, CA, USA), and primers can be seen in Supplementary Table S3. Real-time PCR was performed with the SYBER Premix EX Taq system (Takara, Otsu, Japan) and an ABI Step One System (Applied Biosystems). $\beta$-Actin mRNA levels were used for normalization. Primer sequences for real-time PCR are provided in Supplementary Table S4.

RNA-IP was carried out as described. ${ }^{55}$ Briefly, mouse testes were homogenized in $2 \mathrm{ml}$ of ice-cold lysis buffer (10 mM HEPES, pH 7.4, $200 \mathrm{mM} \mathrm{NaCl}, 30 \mathrm{mM}$ EDTA, $0.5 \%$ Triton X-100) with RNaseOUT (Invitrogen, Carlsbad, CA, USA) and complete EDTA-free protease inhibitor cocktail (Roche, Basel, Switzerland). After removing the nuclear fraction at $3000 \times g$ for $10 \mathrm{~min}$, the $\mathrm{NaCl}$ concentration was raised to $400 \mathrm{mM}$, and clarified at $14000 \times \mathrm{g}$ for $30 \mathrm{~min}$. After $100 \mathrm{mg} / \mathrm{ml}$ yeast tRNA (Sigma, St. Louis, MO, USA) was added to block nonspecific RNA binding, the extracts were precleared with Protein $\mathrm{G}$ agarose (Invitrogen) for $1 \mathrm{~h}$ at $4{ }^{\circ} \mathrm{C}$. A measure of $300 \mu \mathrm{l}$ of the input was saved for RNA and protein analysis. After FMRP monoclonal antibody incubation with recombinant Protein $\mathrm{G}$ agarose for $2 \mathrm{~h}$ at $4{ }^{\circ} \mathrm{C}$, beads were washed three times with lysis buffer containing RNaseOUT. The precleared lysates were immunoprecipitated with antibody-coated recombinant Protein $\mathrm{G}$ agarose at $4^{\circ} \mathrm{C}$ overnight. After washing five times with lysis buffer containing RNaseOUT and $10 \mathrm{mg} / \mathrm{ml}$ yeast tRNA (for the first four washes only), bound RNA was extracted with the mirVana miRNA isolation kit and subjected to real-time RT-PCR using TaqMan assays to quantify mature miRNAs (Applied Biosystems) and SYBR green PCR (Takara) for RNA quantification. U6 RNA was used for normalization to compensate for unspecific miRNA pull-down. mRNA levels were normalized to PGK1.

MiRNA microarray analysis. MiRNA from precleared input lysate (Input) and IP were labeled using the miRCURY Hy3/Hy5 Power labeling kit (Exiqon A/S), and were applied to the miRCURY LNA Array (v.16.0) (Exiqon A/S). All procedures were carried out according to the manufacturer's protocol. Then, the slides were scanned using the Axon GenePix 4000B microarray scanner (Axon Instruments, Foster City, CA, USA). Scanned images were then imported into GenePix Pro 6.0 software (Axon Instruments) for grid alignment and data extraction. Replicated miRNAs were averaged and miRNAs with intensities $\geq 50$ in all samples were chosen for calculating the normalization factor. Expressed data were normalized using the Median normalization. After normalization, differentially expressed miRNAs were identified through fold-change filtering. Hierarchical clustering was performed using the MEV software (v.4.6; TIGR, Boston, MA, USA).

miRNAs were recovered from FMRP-IP of WT mice normalized to Fmr1 KO mice. Differentially expressed miRNAs were defined as genes whose expression in the study group was consistently altered twofold (either greater or less) compared with the control group. Hierarchical clustering for differentially expressed miRNAs was generated by using standard correlation as a measure of similarity.

Luciferase assays. HEK293 cells were co-transfected with $200 \mathrm{ng}$ dual luciferase $3^{\prime}$-UTR reporters, $40 \mathrm{nM}$ miR-383 mimic or $60 \mathrm{nM}$ miR-383 inhibitor using Lipofectamine 2000 (Invitrogen). All experiments were performed in 24-well plates with three replicates for each condition. At 2 days after transfection, luciferase activity was quantified using the Dual Luciferase Reporter Assay System (Promega). Relative expression of reporter constructs was determined by normalizing the ratio of Renilla luciferase activity and firefly luciferase activity to mimic NC or inhibitor NC.

Western blotting. Cells in six-well plates were harvested and mixed with $100 \mu \mathrm{l}$ protein lysis buffer $(50 \mathrm{mM}$ Tris- $\mathrm{HCl}, \mathrm{pH} 7.4,150 \mathrm{mM} \mathrm{NaCl}, 1 \%$ Triton X-100, $1 \%$ sodium dodecyl sulfate, $1 \%$ sodium deoxycholate, $1 \mathrm{mM}$ EDTA) containing complete EDTA-free protease inhibitor cocktail (Roche), $1 \mathrm{mM}$ phenylmethylsulfonyl fluoride and phosphatase inhibitors $(5 \mathrm{mM}$ sodium orthovanadate). Protein lysates were separated on SDS-PAGE gels, electroblotted to a nitrocellulose (NC) membrane (Amersham Biosciences, Freiburg, Germany). Membranes were incubated with antibodies, and visualized by ECL (Kodak, Rochester, NY, USA). Protein levels were normalized to GAPDH and quantified using the Scion Image program 4.0.3.2 (Scion Corporation, Frederick, MD, USA).

Cell proliferation assay and cell cycle analysis. These procedures were carried out using our established method. ${ }^{10}$

In situ hybridization, immunohistochemistry, immunofluorescence and TUNEL. These histological analyses in human and mouse testis tissue were performed essentially as described previously.,10

\section{Conflict of Interest}

The authors declare no conflict of interest.

Acknowledgements. We thank Dr. Stephen T Warren (Emory University) and Dr. Peng Jin (Emory University) for generously donating the FMRP antibody; and Dr. Mian Wu for the HEK293T cell line. This work was supported by the following grants (to FS): the National Basic Research Program of China (2009CB941700); the National Natural Science Foundation of China (81125005 and 31171379); and the Chinese Academy of Sciences Knowledge Creative Program (KSCX2-EW-R-07).

1. Braun RE. Post-transcriptional control of gene expression during spermatogenesis. Semin Cell Dev Biol 1998; 9: 483-489.

2. Bartel DP. MicroRNAs: target recognition and regulatory functions. Cell 2009; 136: 215-233.

3. Bartel DP. MicroRNAs: genomics, biogenesis, mechanism, and function. Cell 2004; 116: 281-297. 
4. Hayashi K, SMCD Lopes, Kaneda M, Tang FC, Hajkova P, Lao KQ et al. MicroRNA biogenesis is required for mouse primordial germ cell development and spermatogenesis. PLoS One 2008; 3: e1738.

5. Korhonen HM, Meikar O, Yadav RP, Papaioannou MD, Romero Y, Da Ros M et al. Dicer is required for haploid male germ cell differentiation in mice. PLoS One 2011; 6: e24821.

6. Papaioannou MD, Pitetti JL, Ro S, Park C, Aubry F, Schaad O et al. Sertoli cell Dicer is essential for spermatogenesis in mice. Dev Biol 2009; 326: 250-259.

7. Wu QX, Song R, Ortogero N, Zheng HL, Evanoff R, Small CL et al. The RNase III enzyme DROSHA is essential for microRNA production and spermatogenesis. J Biol Chem 2012; 287: 25173-25190.

8. Bao J, Li D, Wang L, Wu J, Hu Y, Wang Z et al. MicroRNA-449 and microRNA-34b/c function redundantly in murine testes by targeting $\mathrm{E} 2 \mathrm{~F}$ transcription factor-retinoblastoma protein (E2F-pRb) pathway. J Biol Chem 2012; 287: 21686-21698.

9. Lian J, Zhang $X$, Tian $\mathrm{H}$, Liang $\mathrm{N}$, Wang $\mathrm{Y}$, Liang $\mathrm{C}$ et al. Altered microRNA expression in patients with non-obstructive azoospermia. Reprod Biol Endocrinol 2009; 7: 13.

10. Lian J, Tian H, Liu L, Zhang XS, Li WQ, Deng YM et al. Downregulation of microRNA-383 is associated with male infertility and promotes testicular embryonal carcinoma cell proliferation by targeting IRF1. Cell Death Dis 2010; 1: e94.

11. Yin MM, Lu MR, Yao GD, Tian H, Lian J, Liu L et al. Transactivation of microRNA-383 by steroidogenic factor-1 promotes estradiol release from mouse ovarian granulosa cells by targeting RBMS1. Mol Endocrinol 2012; 26: 1129-1143.

12. Schaeffer C, Beaulande M, Ehresmann C, Ehresmann B, Moine H. The RNA binding protein FMRP: new connections and missing links. Biol Cell 2003; 95: 221-228.

13. Jin $P$, Zarnescu DC, Ceman S, Nakamoto M, Mowrey J, Jongens TA et al. Biochemical and genetic interaction between the fragile $X$ mental retardation protein and the microRNA pathway. Nat Neurosci 2004; 7: 113-117.

14. Cheever A, Ceman S. Phosphorylation of FMRP inhibits association with Dicer. RNA 2009; 15: 362-366.

15. Ishizuka A, Siomi MC, Siomi HA. Drosophila fragile $X$ protein interacts with components of RNAi and ribosomal proteins. Genes Dev 2002; 16: 2497-2508.

16. Jin $\mathrm{P}$, Alisch RS, Warren ST. RNA and microRNAs in fragile $\mathrm{X}$ mental retardation. Nat Cell Biol 2004; 6: 1048-1053

17. Plante I, Davidovic L, Ouellet DL, Gobeil LA, Tremblay S, Khandjian EW et al. Dicer-derived microRNAs are utilized by the fragile $X$ mental retardation protein for assembly on target RNAs. J Biomed Biotechnol 2006; 2006: 64347.

18. Filipowicz W, Bhattacharyya SN, Sonenberg N. Mechanisms of post-transcriptional regulation by microRNAs: are the answers in sight? Nat Rev Genet 2008; 9: 102-114.

19. Jin P, Zarnescu DC, Zhang F, Pearson CE, Lucchesi JC, Moses K et al. RNA-mediated neurodegeneration caused by the fragile $X$ premutation rCGG repeats in Drosophila. Neuron 2003; 39: 739-747.

20. Bassell GJ, Warren ST. Fragile X syndrome: loss of local mRNA regulation alters synaptic development and function. Neuron 2008; 60: 201-214.

21. Garber KB, Visootsak J, Warren ST. Fragile X syndrome. Eur J Hum Genet 2008; 16: 666-672

22. McLennan Y, Polussa J, Tassone F, Hagerman R. Fragile x syndrome. Curr Genom 2011; 12: $216-224$

23. Edbauer D, Neilson JR, Foster KA, Wang CF, Seeburg DP, Batterton MN et al. Regulation of synaptic structure and function by FMRP-associated microRNAs miR-125b and miR-132. Neuron 2010; 65: 373-384.

24. Lu R, Wang HP, Liang Z, Ku L, O'Donnell WT, Li W et al. The fragile X protein controls microtubule-associated protein $1 \mathrm{~B}$ translation and microtubule stability in brain neuron development. Proc Natl Acad Sci USA 2004; 101: 15201-15206.

25. Caudy AA, Myers M, Hannon GJ, Hammond SM. Fragile X-related protein and VIG associate with the RNA interference machinery. Genes Dev 2002; 16: 2491-2496.

26. Kato J, Matsushime H, Hiebert SW, Ewen ME, Sherr CJ. Direct binding of cyclin D to the retinoblastoma gene product $(\mathrm{pRb})$ and $\mathrm{pRb}$ phosphorylation by the cyclin $\mathrm{D}$-dependent kinase CDK4. Genes Dev 1993; 7: 331-342.

27. Mundle SD, Saberwal G. Evolving intricacies and implications of E2F1 regulation. FASEB J 2003; 17: 569-574.

28. Harbour JW, Luo RX, Dei Santi A, Postigo AA, Dean DC. Cdk phosphorylation triggers sequential intramolecular interactions that progressively block $\mathrm{Rb}$ functions as cells move through G1. Cell 1999; 98: 859-869.

29. Hallstrom TC, Mori S, Nevins JR. An E2F1-dependent gene expression program that determines the balance between proliferation and cell death. Cancer Cell 2008; 13: 11-22.

30. Naderi S, Blomhoff HK. Retinoic acid prevents phosphorylation of $\mathrm{pRB}$ in normal human B lymphocytes: regulation of cyclin E, cyclin A, and p21(Cip1). Blood 1999; 94: 1348-1358.

31. Ashley T, Walpita D, de Rooij DG. Localization of two mammalian cyclin dependent kinases during mammalian meiosis. J Cell Sci 2001; 114: 685-693.

32. Hamer G, Roepers-Gajadien HL, van Duyn-Goedhart A, Gademan IS, Kal HB, van Buul PP et al. DNA double-strand breaks and gamma-H2AX signaling in the testis. Biol Reprod 2003; 68: 628-634.
33. Tarsounas M, Davies AA, West SC. RAD51 localization and activation following DNA damage. Philos Trans R Soc Lond Ser B 2004; 359: 87-93.

34. Rogakou EP, Pilch DR, Orr AH, Ivanova VS, Bonner WM. DNA double-stranded breaks induce histone H2AX phosphorylation on serine 139. J Biol Chem 1998; 273: 5858-5868.

35. Sakaguchi K, Herrera JE, Saito S, Miki T, Bustin M, Vassilev A et al. DNA damage activates p53 through a phosphorylation-acetylation cascade. Gene Dev 1998; 12: 2831-2841.

36. Steger K, Aleithe I, Behre H, Bergmann M. The proliferation of spermatogonia in normal and pathological human seminiferous epithelium: an immunohistochemical study using monoclonal antibodies against Ki-67 protein and proliferating cell nuclear antigen. Mol Hum Reprod 1998; 4: 227-233.

37. Yang YY, Xu SL, Xia LX, Wang J, Wen SM, Jin P et al. The Bantam microRNA is associated with Drosophila fragile $\mathrm{X}$ mental retardation protein and regulates the fate of germline stem cells. PLoS Genet 2009; 5: e1000444.

38. Marcon E, Babak T, Chua G, Hughes T, Moens PB. miRNA and piRNA localization in the male mammalian meiotic nucleus. Chromosome Res 2008; 16: 243-260.

39. Yan N, Lu Y, Sun H, Tao D, Zhang S, Liu W et al. A microarray for microRNA profiling in mouse testis tissues. Reproduction 2007; 134: 73-79.

40. Song R, Ro S, Michaels JD, Park C, McCarrey JR, Yan W. Many X-linked microRNAs escape meiotic sex chromosome inactivation. Nat Genet 2009; 41: 488-493.

41. Li JC, Donath S, Li YR, Qin D, Prabhakar BS, Li PF. MiR-30 regulates mitochondrial fission through targeting p53 and the dynamin-related protein-1 pathway. PLOS Genet 2010; 6: e1000795

42. Kulshreshtha R, Ferracin M, Wojcik SE, Garzon R, Alder H, Agosto-Perez FJ et al. A microRNA signature of hypoxia. Mol Cell Biol 2007; 27: 1859-1867.

43. Fasanaro P, D'Alessandra $\mathrm{Y}$, Di Stefano V, Melchionna R, Romani $\mathrm{S}$, Pompilio $G$ et al. MicroRNA-210 modulates endothelial cell response to hypoxia and inhibits the receptor tyrosine kinase ligand Ephrin-A3. J Biol Chem 2008; 283: 15878-15883.

44. Lal A, Navarro F, Maher CA, Maliszewski LE, Yan N, O'Day E et al. MiR-24ilnhibits cell proliferation by targeting E2F2, MYC, and other cell-cycle genes via binding to 'seedless' 3'UTR microRNA recognition elements. Mol Cell 2009; 35: 610-625.

45. Mishra PJ, Song B, Mishra PJ, Wang Y, Humeniuk R, Banerjee D et al. MiR-24 tumor suppressor activity is regulated independent of p53 and through a target site polymorphism. PLoS One 2009; 4: e8445.

46. Bracken AP, Ciro M, Cocito A, Helin K. E2F target genes: unraveling the biology. Trends Biochem Sci 2004; 29: 409-417.

47. Leone G, DeGregori J, Sears R, Jakoi L, Nevins JR. Myc and Ras collaborate in inducing accumulation of active cyclin E/Cdk2 and E2F. Nature 1997; 387: 422-426.

48. Fernandez PC, Frank SR, Wang L, Schroeder M, Liu S, Greene J et al. Genomic targets of the human c-Myc protein. Genes Dev 2003; 17: 1115-1129.

49. Matsumura I, Tanaka H, Kanakura Y. E2F1 and c-Myc in cell growth and death. Cell Cycle 2003; 2 : 333-338.

50. Allingham-Hawkins SJ, Babul-Hirji R, Chitayat D, Holden JJA, Yang KT, Lee C et al. Fragile $\mathrm{X}$ premutation is a significant risk factor for premature ovarian failure: the international collaborative POF in fragile X study - preliminary data. Am J Med Genet 1999; 83: $322-325$

51. Schuettler J, Peng Z, Zimmer J, Sinn P, von Hagens C, Strowitzki T et al. Variable expression of the fragile $X$ mental retardation 1 (FMR1) gene in patients with premature ovarian failure syndrome is not dependent on number of (CGG) $n$ triplets in exon 1. Hum Reprod 2011; 26: 1241-1251.

52. Houldsworth J, Reuter V, Bosl GJ, Chaganti RSK. Aberrant expression of cyclin D2 is an early event in human male germ cell tumorigenesis. Cell Growth Differ 1997; 8: 293-299.

53. Said TM, Paasch U, Glander HJ, Agarwal A. Role of caspases in male infertility. Hum Reprod Update 2004; 10: 39-51.

54. The Dutch-Belgian Fragile X Consortium (D-BFX) Fmr1 knockout mice: a model to study fragile X mental retardation. Cell 1994; 78: 23-33.

55. Brown V, Jin P, Ceman S, Darnell JC, O'Donnell WT, Tenenbaum SA et al. Microarray identification of FMRP-associated brain mRNAs and altered mRNA translational profiles in fragile $\mathrm{X}$ syndrome. Cell 2001; 107: 477-487.

(c) () $\Theta$ Cell Death and Disease is an open-access journal published by Nature Publishing Group. This work is licensed under a Creative Commons Attribution-NonCommercialNoDerivs 3.0 Unported License. To view a copy of this license, visit http://creativecommons.org/licenses/by-nc-nd/3.0/ 